\title{
Clinical and Laboratory Aspects of Filariasis
}

\author{
JAYASRI NANDURI AND JAMES W. KAZURA* \\ Division of Geographic Medicine, Department of Medicine, Case Western Reserve University, and University Hospitals \\ of Cleveland, Cleveland, Ohio 44106
}

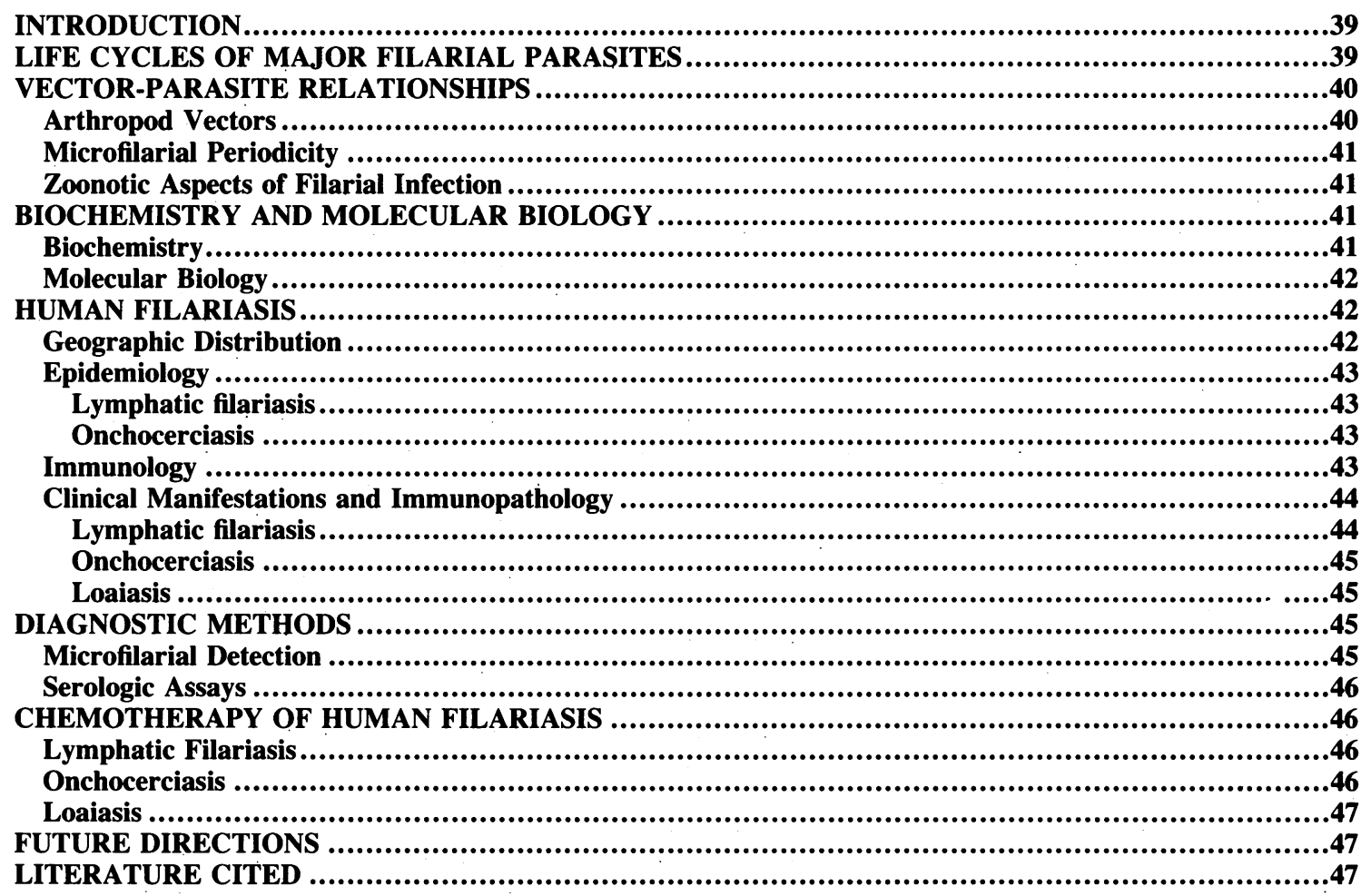

\section{INTRODUCTION}

Filariasis is a group of infectious diseases caused by arthropod-borne nematodes. Several of these parasites, most notably Onchocerca volvulus, Brugia malayi, and Wuchereria bancrofti, are important causes of diseases in humans. Infection is common in many areas of the tropics and constitutes a major public health problem in several geographic regions such as the Indian subcontinent and the South Pacific. In the past few years, attention has been focused on understanding the biological and medical aspects of these diseases, using the newer technologies and analytical approaches of immunology and molecular biology. The present review is intended to summarize the recent advances in these fields as they apply to the diagnosis and control of human filariasis. Because of the relatively greater number of experimental studies of lymphatic filariasis compared with those of onchocerciasis and loaiasis, the former infection will be discussed in greater detail.

Filariae have a remarkable specificity for their definitive mammalian host and obligate intermediate vector species. This specificity is frequently extended even to a favored or obligatory tissue within the host. On the basis of the habitat of the adult worm stage, filarial parasites of medical importance may by classified into three groups: (i) the cutaneous

\footnotetext{
* Corresponding author.
}

group, including Loa loa, $O$. volvulus, Mansonella perstans, and Dipetalonema streptocerca; (ii) the lymphatic group, including $W$. bancrofti, B. malayi, and Brugia timori; and (iii) the body cavity group, including Mansonella ozzardi. $O$. volvulus is the cause of river blindness and several skin diseases. L. loa produces painful dermal reactions. Wuchereria and Brugia species cause elephantiasis and hydroceles. $M$. ozzardi infection is associated with no or only minor disease manifestations and will not be discussed further. The geographic distribution, anatomic site of localization of adult worms, major disease manifestations, and vectors of these parasites are summarized in Table 1. In general, Brugia, Dipetalonema, and Onchocerca species also include several species parasitic for animals. These differ slightly from human parasites in various morphological and physiological characteristics. For example, about eight species of Brugia are recognized. The life cycles, vector-parasite relationships, and epidemiology of these species have been reviewed by Denham and McGreevy (20).

\section{LIFE CYCLES OF MAJOR FILARIAL PARASITES}

The life cycles of the various filariae are similar. Adult male and female worms of Brugia and Wuchereria species inhabit primarily the lumen of lymphatics. $L$. loa and $O$. volvulus adults are located in subcutaneous tissues. Both may migrate in these tissues; $L$. loa may occasionally pass 
TABLE 1. Geographic distribution, anatomic sites of infection, pathogenicity, and vectors of clinically important human filariae

\begin{tabular}{|c|c|c|c|c|}
\hline Organism & Geographic distribution & Pathogenicity & Site of infection & Vector \\
\hline $\begin{array}{r}\text { Wuchereria } \\
\text { bancrofti }\end{array}$ & $\begin{array}{l}\text { Asia, South Pacific, } \\
\text { tropical Africa, } \\
\text { parts of South } \\
\text { America }\end{array}$ & $\begin{array}{l}\text { Lymphangitis, fever, elephantiasis, } \\
\text { hydrocele, chyluria }\end{array}$ & $\begin{array}{l}\text { Lymphatics of } \\
\text { extremities } \\
\text { and genitalia }\end{array}$ & $\begin{array}{l}\text { Culicidae spp. } \\
\text { (mosquito) }\end{array}$ \\
\hline Brugia malayi & South and East Asia & Lymphangitis, fever, elephantiasis & $\begin{array}{l}\text { Lymphatics of } \\
\text { extremities }\end{array}$ & $\begin{array}{l}\text { Culicidae spp. } \\
\text { (mosquito) }\end{array}$ \\
\hline $\begin{array}{l}\text { Onchocerca } \\
\text { volvulus }\end{array}$ & $\begin{array}{l}\text { Africa, Central and } \\
\text { South America }\end{array}$ & $\begin{array}{l}\text { Subcutaneous nodules (onchocercomas), } \\
\text { ocular complications (river blindness), } \\
\text { dwarfism, depigmentation, dermatitis }\end{array}$ & $\begin{array}{l}\text { Subcutaneous } \\
\text { tissues }\end{array}$ & $\begin{array}{l}\text { Simulium spp. } \\
\text { (black fly) }\end{array}$ \\
\hline Loa loa & $\begin{array}{l}\text { Equatorial and West } \\
\text { Africa }\end{array}$ & Skin swellings and allergic reactions & $\begin{array}{l}\text { Subcutaneous } \\
\text { tissues }\end{array}$ & $\begin{array}{l}\text { Chrysops spp. } \\
\text { (deerfly) }\end{array}$ \\
\hline $\begin{array}{l}\text { Mansonella } \\
\text { perstans }\end{array}$ & $\begin{array}{l}\text { Africa and South } \\
\text { America }\end{array}$ & No definite pathogenicity & $\begin{array}{l}\text { Peritoneal and } \\
\text { pleural cavity, } \\
\text { subcutaneous } \\
\text { tissues }\end{array}$ & $\begin{array}{l}\text { Culicoides spp. } \\
\text { (biting midge) }\end{array}$ \\
\hline $\begin{array}{l}\text { Mansonella } \\
\text { ozzardi }\end{array}$ & $\begin{array}{l}\text { Central and South } \\
\text { America }\end{array}$ & No definite pathogenicity & Peritoneal cavity & Culicoides spp. \\
\hline $\begin{array}{l}\text { Dipetalonema } \\
\text { streptocerca }\end{array}$ & Africa & Cutaneous edema, elephantiasis & $\begin{array}{l}\text { Subcutaneous } \\
\text { tissues }\end{array}$ & Culicoides spp. \\
\hline
\end{tabular}

through the corneal conjunctiva. Adult worms of lymphatic filariae may live for 7 to 10 years, although cases of 40 -year longevity have been reported (73). The sexually mature adult is the largest of all stages. It is long and slender with blunt ends. Male worms vary from 20 to $40 \mathrm{~mm}$ in length in the cases of W. bancrofti, B. malayi, and L. loa and from 19 to $42 \mathrm{~mm}$ in $O$. volvulus. Female worms of $W$. bancrofti and $O$. volvulus are longer (6 to 10 and 33 to $50 \mathrm{~cm}$, respectively) than B. malayi and L. loa females (80 to 100 and 20 to $70 \mathrm{~mm}$, respectively). Adult female filariae are ovoviviparous, producing thousands of microfilariae or first-stage larvae after fertilization by adult male parasites. Microfilariae of Wuchereria, Brugia, and Loa species retain the egg membrane as a sheath. In the cases of Wuchereria and Brugia species, microfilariae migrate from the lymphatics into the bloodstream; Loa and Onchocerca microfilariae appear in the peripheral blood and under the skin, respectively. These parasite stages are ingested by the intermediate arthropod host with the blood meal. Mosquitoes act as the intermediate hosts of Wuchereria and Brugia species; black flies (Simulium spp.) and deerflies (Chrysops spp.) are the vectors of $O$. volvulus and $L$. loa, respectively. Ingested microfilariae penetrate the gut wall and eventually reach the thoracic musculature or fatty tissues of the invertebrate host, where they shorten by metamorphosis into sausage-shaped bodies 240 to $250 \mu \mathrm{m}$ in length in the case of lymphatic filariae. At this stage of development, the first true molt occurs, after which the tail portion atrophies and the intestinal tract of the helminth becomes well defined. A second molt follows, and the infective larvae at this stage are slender and measure 1.4 to $2 \mathrm{~mm}$ in length. The period of time from ingestion of microfilariae to maturation of infective larvae is 10 to 14 days for lymphatic filariae and 5 to 8 days for $O$. volvulus. These third-stage larvae move to the labium or proboscis sheath of the mosquito or fly and infect a new host when the insect feeds. They enter the skin through the wound made by the insect, molt to fourth-stage larvae, and eventually develop into sexually mature adult worms. The prepatent period (the time from infection to detection of microfilariae released by fecund adult female worms) is approximately 1 year for the major human filarial parasites. This period is considerably shortened (to 10 to 12 weeks) in rodents such as jirds (Meriones unguiculatus) experimentally infected with $B$. malayi (20).

\section{VECTOR-PARASITE RELATIONSHIPS}

\section{Arthropod Vectors}

The known mosquito vectors of $W$. bancrofti, B. malayi, and $B$. timori belong to four main genera: Anopheles, Aedes, Culex, and Mansonia (127). The efficiency of specific mosquito species to transmit filarial infection to humans is determined by multiple factors. Some species do not transmit the parasite because ingested microfilariae fail to develop to infective forms in the insect. Some mosquitoes may be poor vectors because their population density is too low or simply because they do not bite humans; i.e., they either are autogenous or feed extensively on other animals. Several reviews describing the relationship of mosquito vectors to transmission of human lymphatic filariasis have been published $(83,144)$. A large body of information on the taxonomy, bionomics, and control of mosquito populations is available (84).

The bionomics and taxonomy of Onchocerca vectors have been extensively reviewed $(18,74-76,88)$. The most important vector of $O$. volvulus in Africa is the blackfly, Simulium damnosum. In Guatemala and Mexico, S. callidum, $S$. metallicum, and $S$. ochraceum have been incriminated as vectors. Local simulid vectors are more efficient intermediate hosts of the local parasite strain than vectors from other geographic regions. Duke et al. $(34,35)$ have shown that, when $S$. ochraceum was fed on Guatemalan and African patients, the simulid ingested 20 to 25 times more microfilariae of the Guatemalan strain than of the African strain. The periodicity of $O$. volvulus microfilariae appears to be an adaptation to the biting cycle of the local insect vector in much the same way as Wuchereria and Brugia species (30, 32). In addition, the vectors of each geographical region are well adapted to biting the appropriate area of the skin of the local human host. For example, the short scarifying proboscis of $S$. damnosum is ideally suited to penetrate just deeply enough to pick up microfilariae from beneath the epidermis (33). $S$. ochraceum is well adapted to transmit the Central American form of $O$. volvulus by virtue of the fact that it tends to bite the upper part of the torso and head, where microfilariae are concentrated in infected hosts of the local strain of $O$. volvulus (19).

The vectors of $L$. loa are species of Chrysops (deerflies) which differ greatly from mosquitoes, black flies, and biting 
midges. The two principal vectors of loaiasis in Africa are Chrysops silacea and $C$. dimidiata, both of which are active by day (28).

\section{Microfilarial Periodicity}

$W$. bancrofti and $B$. malayi microfilariae have unique circadian rhythms manifested as a variability of their number or concentration in the peripheral circulation $(53-56,130)$. They can be classified into two general groups on this basis: (i) the nocturnally periodic strain and (ii) the nocturnally subperiodic strain. The former have peak concentrations from 2200 to $0200 \mathrm{~h}$; no or very few parasites are detectable in peripheral blood during the daytime hours. The nocturnally subperiodic strains also exhibit their highest levels of parasitemia at night, but 40 to $60 \%$ of peak levels persist during the day. In addition to these two basic strains, a third form, the nonperiodic or diurnally subperiodic, in which there is little variation with time of day has been described $(27,52)$. The mosquitoes, the vectors of Wuchereria and Brugia species, also have a circadian rhythm which describes their feeding time. The highest concentration of microfilariae in the peripheral blood occurs at a time concurrent with the period of most active feeding by the local vector. This coincidence suggests that the parasites have adapted their periodicity to the vector feeding behavior, possibly to facilitate their transmission (138). Thus, the diurnally subperiodic form of $W$. bancrofti in the South Pacific is transmitted mainly by day-biting mosquitoes of the genus Aedes, which are poor vectors of the nocturnally periodic strain. This relationship is reversed for nocturnally periodic $W$. bancrofti and its mosquito vector, Culex fatigans. Similarily, in the case of $L$. loa, the appearance of microfilariae in large numbers in the host peripheral circulation during the day coincides with the active feeding period of Chrysops species that serve as its vectors.

The periodicity of Wuchereria and Brugia species is dependent primarily on the daily activities of the host and not on alternations of day and night. Thus, if the human host reverses its routine sleep-and-wake cycle, the periodicity of microfilaremia is also reversed. Studies of Wuchereria and Brugia species suggest that their periodicity is due to differences in the oxygen tension between the arterial and venous blood in the lungs $(6,55)$. When microfilariae are absent from peripheral circulation, they accumulate primarily in the arterioles of the lungs. Hawking suggested that, if the difference in the arterial-venous oxygen tension is $<50 \mathrm{~mm}$ $\mathrm{Hg}$, microfilariae will accumulate in the lungs $(53,56)$. When the pulmonary arterial-venous oxygen tension difference exceeds $50 \mathrm{~mm} \mathrm{Hg}$ during sleep, microfilariae migrate from the pulmonary vasculature and appear in the peripheral circulation (55). With respect to $O$. volvulus, nothing is known about the mechanisms controlling the periodicity of migration of microfilariae in the skin (36).

Morphologic criteria have been used to distinguish various species of microfilariae. These include mean length (220 to $290 \mu \mathrm{m}$ ), the presence of caudal nuclei, and, most important, the presence or absence of a sheath (present in Brugia, Wuchereria, and Loa species; not present in $O$. volvulus) $(20,51)$. Except for the latter criterion, a great deal of experience and time are necessary to obtain reproducible data in this manner. The periodic strains of Brugia species also differ from subperiodic forms in the following ways: (i) a relatively greater proportion of the former strain lose their sheath when stained with Giemsa; (ii) Formalin-fixed microfilariae of periodic forms have a greater mean length; and (iii) the periodic forms have higher indices of infection in experimental Anopheles mosquitoes, while the reverse is true with Mansonia mosquitoes (145).

\section{Zoonotic Aspects of Filarial Infection}

Unequivocal proof that a filarial infection is a zoonosis, i.e., an infection transmitted naturally from animals to humans, is difficult to obtain because invertebrate stages of animal and human parasites are similar morphologically. However, the relative susceptibility of humans and other animals to infection and the host preferences of mosquitoes have been utilized to classify in a general way whether or not the various types of filariases exist as zoonoses. The nocturnally periodic strain of $\boldsymbol{B}$. malayi is not a zoonosis because the anopheline and aedine vectors of this strain are found mainly in agricultural areas, where both the number and diversity of wild animals are limited (69). The few cases of domestic infections involving animals such as cows, goats, cats, and dogs are thought to be infections most likely derived from humans. In contrast, the subperiodic strain of $B$. malay is thought to be a zoonosis. Mansonia mosquitoes, the vector of this strain, normally feed on humans and wild animal hosts such as forest monkeys $(145,146)$.

Onchocerca infection is not generally classified as a zoonosis. Although natural infection has been recorded in spider monkeys (7) and gorillas (133) and the chimpanzee is a good laboratory host for $O$. volvulus (29), these animals are not thought to represent an important reservoir of human onchocerciasis. Studies conducted in West Africa suggest that a species of Onchocerca related to $O$. volvulus may represent a zoonosis transmitted by $S$. damnosum $(25,30,42)$. As is the case for Brugia species, it is difficult to distinguish Onchocerca microfilariae and adult worms isolated from humans from those of cattle and wild antelopes. Cameron (8) and Strong (128) suggest that these animals might be involved in transmission. In some parts of Africa, it is thought that the same species of simulid may be transmitting both bovine and human Onchocerca species. Utilization of deoxyribonucleic acid (DNA) probes specific for human or animal parasites may eventually provide an effective means of solving these important problems (86).

The situation with respect to $L$. loa is similar to that with $O$. volvulus. Nonhuman primates such as the drill may be infected with human strains, but these or other animals are not thought to be important reservoirs of infection for human populations (96).

\section{BIOCHEMISTRY AND MOLECULAR BIOLOGY}

\section{Biochemistry}

The biochemistry of filarial nematodes has been difficult to study because of their complex life cycle. Each parasite stage is necessarily adapted to its specific environmental conditions such as temperature, $\mathrm{pH}$, and oxygen tension. Elaborate mechanisms involving rapid changes from aerobic to anaerobic metabolism and invertebrate to vertebrate body temperature must therefore operate. Although little is known about these events in human filariae, results of studies of animal parasites such as B. pahangi, Acanthocheilonema viteae, and Dirofilaria immitis may provide some insight.

Feeding by nematodes was previously considered to occur exclusively via their gut because the cuticle was thought to be impermeable to nutrients $(104,135)$. However, recent in vitro studies indicate that the filarial cuticle, as well as the 
gut, is a major route of entry for amino acids, monosaccharides, and dyes (11). Tissue uptake indices of different nonelectrolytes in $B$. pahangi and $A$. viteae, animal filariae closely related to $B$. malayi, suggest that uptake of a molecule has no obvious relationship to its lipophilic character (17).

There is only scant knowledge of the biosynthetic pathways of nucleic acids and lipids in filarial nematodes, primarily because of a lack of fully defined and successful in vitro culture conditions that permit expression of the complete parasite life cycle. Studies by Longworth et al. have shown that $B$. malayi microfilariae and adult worms incorporate exogenous long-chain fatty acids such as arachidonic, palmitic, oleic, and linoleic acids $(77,78)$. Arachidonic acid is rapidly esterified into phospholipids including phosphatidylinositol. Esterification of other fatty acids into phospholipids is quantitatively less and involves incorporation into phosphatidylcholine and phosphatidylethanolamine. Recent experiments indicate that microfilariae may metabolize host platelet eicosanoids in a manner which leads to production of biologically active lipids such as 12-hydroxyeicosatetraenoic acid (L. Liu and R. F. Weller, Clin. Res. 36:461, 1988). Jaffe and Chrin (61) have shown that B. pahangi and Dirofilaria immitis microfilariae carry out purine synthesis de novo. These parasites also possess purine salvage pathways. It is not clear why two separate routines for purine synthesis coexist in these organisms. In vitro studies demonstrate that adult filarial nematodes including $B$. pahangi, $O$. volvulus, and $A$. viteae rapidly take up glucose via a transcuticular route (114). These parasites rely heavily on glycolysis for energy production, and 10 to $20 \%$ of the glucose taken up is converted to glycogen. In $B$. pahangi and $A$. viteae, the primary product of metabolism is lactate, indicating that the worms are primarily homolactate fermenters (138). The release of small amounts of succinate suggests that a partially reversed tricarboxylic acid cycle is also active in these filarial nematodes (114).

Oxygen consumption and oxidative phosphorylation may represent important metabolic facets of filarial nematodes. Low oxygen tension is required for in vitro growth, molting, and differentiation of $B$. pahangi and $A$. viteae (40). Measurable rates of exogenous oxygen uptake have been demonstrated for adult $A$. viteae, Dirofilaria immitis, and $B$. pahangi. However, cytochrome $c$ and cytochrome $c$ oxidase were not detected in these systems. Mendis and Townson demonstrated the presence of a classical respiratory electron transport sequence in adult $B$. pahangi and $A$. viteae (87).

Another aspect of filarial metabolism which needs further study is the toxic nature of oxygen for these organisms. Scavenger enzymes such as catalase, superoxidase dismutase, and glutathione peroxidase and vitamins such as vitamin $C$ and ascorbic acid are important antioxidants (142). Several investigators have reported the uptake and existence of retinol (vitamin A) as well as its formation from betacarotene in $O$. volvulus and $B$. pahangi. The retinyl phosphate formed from retinol may be involved in glycoprotein synthesis (14).

The mechanisms by which filarial worms penetrate and migrate within host tissues remain largely unknown. $O$. volvulus and $B$. malayi contain and release proteolytic enzymes that solubilize collagen molecules from native type I collagen fibers (108). Further studies are needed to characterize and determine the role of proteases in the life cycle of the parasite.

\section{Molecular Biology}

Several groups of investigators have recently reported the use of DNA probes to distinguish between different species of filarial parasites. Filariae in potential animal reservoirs of human infection could be identified with these probes and distinguished from morphologically similar human parasites. Three different probes for $O$. volvulus which show different degrees of cross-reactivity with genomic DNAs from other filarial species have been described $(106,122)$. Erttmann and co-workers (37) have isolated a clone, pFS-1, which hybridizes to $O$. volvulus adult worm DNA isolated from persons in the forest region of West Africa, but not to that of the savannah region. McReynolds et al. have constructed two oligonucleotide probes from a highly repeated sequence of $B$. malayi DNA (86). Both are sensitive and species specific for $B$. malayi and B. pahangi. Species-specific DNAs may also be useful for detecting the presence of human filariae in vector populations $(123,124)$.

Recombinant DNA technology has also provided an avenue for obtaining substantial quantities of defined parasite antigens to examine details of the immune response and for vaccine development. Nilsen and co-workers have identified and characterized a recombinant clone from an adult $B$. malayi complementary DNA expression library that corresponds to a potentially protective native antigen $(90)$. The full-length complementary DNA corresponding to this antigen has been engineered into a vaccinia construct and shown to lower the level of $B$. malayi microfilaremia in jirds immunized with this preparation (J. Kazura, W. Kroeze, K. Perrine, C. Langford, and T. Nilsen, Clin. Res. 36:579, 1988). Arasu et al. (2) have identified several $B$. malayi recombinant clones encoding antigens, some of which are specific for the genus, some of which are specific for $B$. malayi only, and some of which are cross-reactive among different species. Their possible use as diagnostic reagents or protective antigens has not been tested.

\section{HUMAN FILARIASIS}

\section{Geographic Distribution}

The geographic distribution of various types of human filariasis is accounted for primarily by the existence of the obligate arthropod vector in sufficient numbers to maintain the parasite life cycle in the ecosystem. Improved sanitation conditions in developed countries of Europe and North America have reduced breeding sites for mosquitoes to a level which no longer sustains transmission of human lymphatic filariae. Conversely, poor sanitation, increasing urbanization, and a requirement of rural populations in arid regions to live near rivers have fostered the spread of lymphatic filariasis and onchocerciasis in many developing countries.

$W$. bancrofti infection exists in greatest numbers in tropical and subtropical Asia, Africa, and the South Pacific. Caribbean nations, such as Haiti, and coastal areas of Brazil are also endemic foci, generally with lower intensities of infection than those observed in Asian countries. B. malayi infection is limited to southern China, Malaysia, the Philippines, and a few areas of India. B. timori infections occur only on the Indonesian islands of Timor and Flores (20). It has been estimated that $\sim 90$ million people worldwide are infected with lymphatic filariae (96).

$O$. volvulus is found in Central America, Africa, and the Arabian peninsula. The largest number of infected persons 
live in a region encompassing West Africa (e.g., countries including Liberia, Ivory Coast, and Mali) to East African countries such as the Sudan. Smaller foci of infection exist in Venezuela, Colombia, and Brazil. Approximately 30 to 40 million people worldwide are infected with $O$. volvulus (119).

Loaiasis occurs only in rain forest areas of western and central Africa and parts of the Sudan. $M$. perstans is endemic in Africa and South America, while D. streptocerca occurs only in the tropical rain forest zone of Africa. $M$. ozzardi infection is present in various Caribbean islands and parts of South America. The specific foci of the various human filariases are extensively reviewed in the monograph by Sasa (116).

\section{Epidemiology}

Definition of the prevalence and intensity of filarial infections is important for several reasons. First, in epidemiologic investigations, the extent of infection and disease in a population provide information necessary for rational allocation of limited financial resources. Second, by this approach, the relationship of infection intensity to clinical sequelae and morbidity on a community level can be assessed. Third, epidemiologic data are crucial in evaluating the impact of control measures such as vector eradication, chemotherapy, or a vaccine. In this section, lymphatic filariasis and onchocerciasis are discussed in terms of their distribution within communities in endemic areas. Other filarial infections are not discussed.

Lymphatic filariasis. The most important factor determining the overall prevalence of infection in a community is the frequency of exposure to infective third-stage larvae (111). Because environmental conditions vary enormously among endemic areas, there may be marked differences in the ageand sex-specific prevalences and intensities of infection (measured by the number of microfilariae per volume of blood; see discussion below) in different areas of the world or even the same country. For example, adult male residents of a barrio in Luzon, Philippines, were reported to have 5- to 10 -fold-higher intensities of $W$. bancrofti microfilaremia than female residents of similar age (49). These differences in intensity of parasitemia were related to the behavior of the local arthropod vectors and the social habits of persons in the community. Aedes poecilus, the major vector of $W$. bancrofti in the area, breeds in axils of abacá plants and has a restricted flight distance. Children and women generally do not spend much time near the plants, which are located several kilometers from the village. On the other hand, men are involved in cultivating and stripping abacá and may sleep in the vicinity, thereby increasing their chances of coming in contact with the vector (132). In the absence of these or other peculiarities, however, a general pattern of infection is observed in many endemic areas. Patent microfilaremia is first detected in 5 to 10 year olds, the prevalence ranging from $<10 \%$ in regions where transmission is low to $>20 \%$ where transmission is intense (e.g., some rural areas of Papua New Guinea) $(20,21,66,115)$. The prevalence of parasitologically confirmed infection gradually increases in persons up to the age of 30 to 40 years, after which it remains the same or decreases. Such findings have been reported in surveys of $W$. bancrofti infection conducted in Bangladesh (148), Kenya (146), and Egypt (125), B. malayi infection in several areas of Southeast Asia (reviewed in reference 20), and $B$. timori infection in Indonesia $(21,105)$.

Several factors other than exposure to vectors harboring third-stage larvae may influence the prevalence of infection.
Transplacental immunity and breast-feeding may affect the prevalence and intensity of infection, especially in children $<5$ years old. Studies of experimental rodent hosts suggest that offspring of previously infected mothers may have a greater degree of resistance to infection than those of uninfected mothers (118). The decrease in the prevalence and intensity of microfilaremia in persons in the fifth decade of life and beyond suggests that some residents of endemic areas acquire protective immunity to filariae with repeated exposure (120). Longitudinal observations of infected human populations will be required to confirm this interpretation since age-related changes in contact with the mosquito vector and insensitivity of methods of parasitologic diagnosis may account in part for the decreased intensity of parasitemia in older individuals.

As is the case with other nonfilarial helminthic infections, only a minority of infected individuals develop severe irreversible disease. Obstructive lymphatic disease characterized by unremitting elephantiasis of an extremity or hydrocele (see below) occurs in 1 to $30 \%$ of residents of endemic areas. The prevalence of more subtle clinical effects, such as altered capacity to work and susceptibility to other infections common in the endemic area (e.g., malaria), have not been studied in detail. Differences in well-defined disease manifestations among populations in various endemic areas depend primarily on the cumulative number of infective larvae to which individuals are exposed $(96,98,111)$. The type, severity, and absence or presence of specific disease syndromes attributable to lymphatic filariae result from a more complex series of events that includes, most importantly, host immune reactivity (see below).

Onchocerciasis. Age-specific prevalence and intensity of $O$. volvulus infection increase between childhood and middle age and plateau or decrease thereafter $(5,15,44,119)$. The frequency of its most debilitating disease manifestation, blindness, correlates roughly with the number of microfilariae which migrate to the eye and, inferentially, the intensity of exposure to infective larvae transmitted by the black fly vector (31). Immune complex deposition and other aspects of the immune response likely play a major role in determining the type and severity of disease sequelae suffered by persons infected with $O$. volvulus $(41,45,81,88,89,103$, $126,139)$. Relatively little information is available on this subject because nonprimate models of $O$. volvulus infection do not exist and direct study of the human eye is difficult or impossible in many areas of the tropics where onchocerciasis is endemic.

Studies of onchocerciasis in the field have generated equations which are useful for estimating and comparing the exposure risk in different endemic areas $(30,31,33-35)$. These equations derive from the number of fly bites per human observed over an 11-month period and the number of infective larvae per trapped, dissected fly. The annual transmission potential and annual biting rate are calculated with the respective formulas: (number of flies caught over 11 months $\times$ number of infective larvae)/number of flies dissected, and (number of flies caught $\times$ number of days in month)/number of days worked. The annual biting rate has been shown to correlate directly with the frequency of blindness in an endemic area of West Africa.

\section{Immunology}

The immune response to filarial infection has been the subject of intense investigation, and several excellent reviews have recently been published $(46,81,89,97,111,120$, 
129). Because of the complex nature of this subject and the relative paucity of studies of onchocerciasis and loaiasis, this section primarily describes the most recent investigations of the human immune response to lymphatic filariae.

The most consistent finding of studies conducted in several endemic areas is marked suppression of cell-mediated immunity to mitogens $(110)$ and filarial antigens $(109,112)$. This phenomenon has been reported in both bancroftian and brugian filariasis and has been demonstrated reproducibly as a reduction in in vitro $\mathrm{T}$-lymphocyte blastogenesis in response to crude parasite extracts. The basis for this alteration in immune reactivity is not related to an inability of target lymphocytes to respond but to the presence of suppressor mononuclear cells (112). Correlation of these responses with microfilarial status and longitudinal studies of individuals before and after administration of antimicrofilarial chemotherapy indicates that high "microfilarial burdens" result in diminished and actively suppressed immunity to filarial antigens (113). These responses may benefit not only the parasite by allowing it to escape damage by host immune mediators but also the infected individual, who may temporarily avoid the pathologic consequences of immune reactivity. The recent development of a nude mouse model of lymphatic inflammation associated with Brugia infection (134) and measures of granulomatous reactions in jirds (62) should be useful in assessing the veracity of this concept. In addition, identification of the specific filarial antigens which elicit and modulate T-cell responses will be helpful in designing methods to control undesirable consequences of cellmediated immunity. The recent description of $\mathrm{T}$-cell clones responsive to filarial extracts (93) and identification of several $O$. volvulus complementary DNA clones encoding polypeptides that drive lymphocyte proliferation of cells from infected donors (131) should aid in dissecting this important aspect of immunity.

An exceedingly complex humoral immune response to filarial parasites develops during the course of infection. Unlike bacteria and most unicellular pathogens, multiple stages of filariae may simultaneously exist in the host. Each may contain distinct antigens that are not only displayed on the parasite surface but also released as metabolic products $(71,82)$. These molecules elicit high titers of immunoglobulin $M$ (IgM), IgG, and IgE antibodies, especially in amicrofilaremic individuals $(59,83,97)$. Although $\mathrm{IgE}$ antibodies are generally associated with allergic responses, such clinical reactions are uncommon in persons residing in endemic areas. This may in part be related to concurrent development of IgG "blocking" antibodies $(59,60,102)$. Recent studies of Hussain and co-workers (58) demonstrate that specific subclasses of IgG antibody may be involved in determining the outcome of infection. IgG4 antibodies were present in significantly higher titers in asymptomatic microfilaremic subjects than in symptomatic amicrofilaremic persons with elephantiasis. These antibodies did not react with a restricted set of filarial antigens in immunoblotting studies but rather with molecules of 10,000 to $>100,000 M_{\mathrm{r}}$. Elucidation of this aspect of the immune response will be facilitated by continued efforts to purify and define the stage specificity of native antigens $(10,71)$ that drive $\mathrm{B}$-lymphocyte responses $(70,91)$ and to clone immunologically relevant antigens $(2$, $121,147)$.

To date, protective immunity in human lymphatic filariasis has not been proven. However, epidemiologic surveys described in a previous section of this review and experimental studies in animal models of filariasis $(20,57,64,65,95,141)$ suggest that partial resistance to filarial infection may de- velop in some residents of endemic areas. For example, mice immunized with $B$. malayi microfilarial antigens of 25,000 and $60,000 M_{\mathrm{r}}$ demonstrate enhanced clearance of microfilaremia. In addition, amicrofilaremic subjects with bancroftian filariasis have higher titers of IgG antibodies to the lower- $M_{\mathrm{r}}$ antigen compared with age-matched microfilaremic persons (63). The $60,000-M_{\mathrm{r}}$ antigen has recently been cloned (90), and preliminary studies indicate that vaccination of jirds with the cloned molecule induces reduced levels of microfilaremia (Kazura et al., Clin. Res. 36:579, 1988). Passive transfer of a murine monoclonal antibody to a candidate protective antigen of $70,000 M_{\mathrm{r}}$ has also been shown to decrease transiently the level of microfilaremia in B. malayi-infected jirds (9).

\section{Clinical Manifestations and Immunopathology}

Unlike bacterial, viral, and protozoan pathogens, inoculation of the host with a small number of infective helminths generally does not result in clinically overt disease. Repeated and/or acute heavy exposure is required, in large part because adult-stage organisms do not multiply within the host. Filariae are not directly pathogenic by virtue of their large size but elicit host immune responses which may not only mediate resistance but also underlie disease manifestations such as lymphatic or ocular inflammation.

Lymphatic filariasis. The spectrum of disease manifestations of lymphatic filariasis has been described in a practical and clinically useful manner by Ottesen $(96,98)$. At one extreme, residents of endemic areas are amicrofilaremic and lack disease attributable to lymphatic filariasis. It is presumed that these subjects are exposed to infective larvae with a frequency similar to that of other persons residing in the same endemic region. Such individuals may be "partially" resistant to infection and exhibit high lymphocyte proliferative responses to filarial antigens. Next in degree of severity are asymptomatic subjects with microfilaremia. Many individuals in this category have $\mathrm{T}$ lymphocytes which are specifically unresponsive to filarial antigens prepared from worms solubilized in aqueous buffers (109). The third category includes persons with filarial fevers, retrograde lymphangitis, lymphadenitis, and inflammation of the lymphatics of the male genitalia (epididymitis, thickening of the spermatic cords, transient hydrocele or testicular swelling). Microfilaremic teenagers and young adults experience these syndromes, which last several days and may recur five to eight times per year. Inflammation in the lymphatics may be due to hypersensitive immune reactions to developing or molting larvae $(130,131,136)$. Detailed immunologic studies have not been performed in this group of infected individuals. Persons who have not previously lived in an endemic area but are exposed to a large number of infective larvae over a short period of time may suffer a similar clinical syndrome. In contrast to their counterparts in endemic areas, these individuals rarely have microfilariae detectable in the bloodstream. American servicemen stationed in the South Pacific during World War II exemplify this situation (13). Continued exposure of residents to infective larvae may eventually result in chronic obstructive lymphatic disease. These signs generally are not evident until the age of 30 to 40 years or older.

Histologically, the afferent lymphatics of these persons contain mononuclear cells, eosinophils, and collagenous deposition indicating fibrosis (137). Functional lymphatic vessel incompetence accompanies these pathologic changes and results in an inability of lymph to be transported 
centrally. In brugian filariasis, this is manifested as elephantiasis of the upper or lower extremities or both. Bancroftian filariasis causes elephantiasis of the extremities (especially the legs) and breasts as well as involvement of the male genitals, characterized by irreversible hydroceles and thickening of the vas deferens (26). Individuals with these severe disease manifestations are usually amicrofilaremic, although microfilaremia may persist in persons living in areas where transmission is intense. Persons with these severe disease manifestations tend to have relatively high antimicrofilarial antibody titers (85) and vigorous lymphocyte proliferative responses to antigens derived from adult-stage parasites (110).

At the opposite end of the spectrum from amicrofilaremic asymptomatic subjects are persons with the tropical eosinophilia syndrome. Hypersensitivity responses predominate early during the course of filarial infection in persons with tropical eosinophilia (101). The syndrome occurs most commonly in restricted geographic regions such as southern India and is characterized by extreme elevations of serum $\operatorname{IgE}(>5,000 \mathrm{U} / \mathrm{ml})$, high IgE and IgG anti-microfilarial antibody titers, amicrofilaremia, nocturnal asthmatic symptoms, and eosinophilia. Administration of diethylcarbamazine (DEC) results in prompt clinical resolution of symptoms. If tropical eosinophilia syndrome remains untreated, chronic restrictive pulmonary disease may develop. The pathologic response in tropical eosinophilia syndrome is likely secondary to local immune reactivity to microfilariae in the pulmonary vasculature (101). Eosinophil accumulation in the lung and release of potentially toxic molecules such as cationic proteins and reduced oxygen products may cause tissue damage, with subsequent fibrosis.

Onchocerciasis. The major clinical signs of onchocerciasis include dermatitis, subcutaneous nodules, lymph node enlargement, and eye disease $(1,128)$. Skin disease is most frequently manifest as pruritus with excoriations secondary to scratching. Erythema is also seen in many individuals. If infection persists, elastic fibers are gradually lost, with consequent skin wrinkling and atrophy (16). Hypo- and hyperpigmentation of the skin are especially common in individuals living in the rain forest areas of Africa (1). Skin biopsies of asymptomatic or mild cases reveal microfilariae in the upper epidermis with scant cellular reaction. Mononuclear cells and eosinophils are present in specimens obtained from persons with persistent disease and in those to whom antimicrofilarial chemotherapy has recently been given $(15,16)$. Inflammatory cells are localized around blood vessels and in dermal appendages. Subcutaneous nodules or onchocercomata contain adult worms. These nodules are painless and several centimeters in diameter and tend to be localized near the pelvis in Africans and the upper torso and head in Central Americans. The lesions consist of an outer border of scar tissue surrounding adult worms, eosinophils, and mononuclear cells $(68,81)$. Older onchocercomata may calcify, become firm to palpation, and contain necrotic material. In $O$. volvulus infection, lymphatic disease is less common than in filariasis and tends to occur in the inguinal and femoral areas in Africans. In its most severe degree, pendulous lesions known as "hanging groin" may develop. These consist of a massively enlarged lymph node and surrounding edematous skin (42). Ocular disease is the most devastating manifestation of onchocerciasis and accounts for its colloquial name, river blindness. It is one of the leading preventable causes of blindness worldwide $(44,81,88,119)$. In increasing order of clinical severity are conjunctivitis with photophobia, punctate keratitis, and sclerosing keratitis.
Chorioretinitis, anterior uveitis, and optic neuritis are less common. Serious eye disease is more common in the savannah than rain forest areas of Africa (34, 35). Punctate keratitis appears to be a result of an acute cellular inflammatory response to microfilariae dying in the cornea. The pathogenesis of other forms of eye disease is not known, although it is suspected that deposition of parasite antigenantibody complexes plays a role $(46,47,81,97)$.

Investigations of the relationship of clinical manifestations to immune reactivity suggest that, like lymphatic filariasis, disease secondary to $O$. volvulus infection is a consequence of the host immune response $(79,81,100)$. In vitro hyporesponsiveness of lymphocytes to parasite antigen has been reported in persons with microfilaridermia when compared with endemic controls without detectable microfilariae in the skin $(41,45,139)$.

Loaiasis. Infection with $L$. loa causes distinct syndromes in lifetime residents of endemic areas of West and Central Africa and previously uninfected visitors to these areas. In the case of long-term residents, the majority are asymptomatic or only occasionally develop Calabar swellings (38). These migratory lesions are erythematous and angioedematous and up to $10 \mathrm{~cm}$ in diameter, occur most frequently on the extremities, and may migrate. They last from 1 to several days and may be recurrent. Their pathogenesis is not clearly established, although it is likely that they represent immune reactions to migrating adult $L$. loa. In subcutaneous tissues of residents, adult worms also are evident as calcified parasites on radiographic examination and by direct visualization of worms passing through the conjunctiva. Visitors to endemic areas demonstrate a markedly greater degree of hypersensitivity-type reactions to $L$. loa infection (92). Calabar swellings are more frequent and painful, larger, and accompanied by hyperimmunoglobulinemia, particularly $\mathrm{IgE}$, and amicrofilaremia. Recent studies indicate that $\mathrm{T}$ lymphocyte hyperresponsiveness and dysregulation of $\mathrm{B}$ cell IgG and IgE anti-parasite antibody production in vitro are associated with these clinical manifestations (94).

\section{DIAGNOSTIC METHODS}

\section{Microfilarial Detection}

The only unequivocal means of ascertaining active filarial infection is by demonstrating parasites in host tissue. In the cases of lymphatic filariasis and loaiasis, this is most commonly achieved by detection of microfilariae in the bloodstream. Adult L. loa may occasionally be observed passing through the conjunctiva. Blood samples should be obtained at a time of day consistent with the known periodicity of microfilariae in the specific geographic region, which is between 2200 and $0200 \mathrm{~h}$ for nocturnally periodic forms of brugian and bancroftian filariasis. L. loa microfilaremia has a peak intensity at $1200 \mathrm{~h}$.

Various techniques for identification of microfilariae in blood have been utilized. These range from a Giemsa smear of a $20-\mu$ l blood sample obtained by finger prick to concentration methods utilizing a larger volume of blood. The Knott concentration method involves fixing a $1-\mathrm{ml}$ sample of anticoagulated blood with 4 volumes of Formalin. A sediment is then prepared and examined microscopically for microfilariae (96). The Nuclepore (Nuclepore Corp., Pleasanton, Calif.) method uses a polycarbonate filter through which 1 to $2 \mathrm{ml}$ of anticoagulated blood is passed. The filter is then removed from the supporting chamber and placed on a microscope slide for counting of parasites. This method is 
extremely sensitive and ideally suited to epidemiologic surveys in which quantification of microfilaremia is important (23).

Microfilariae of $O$. volvulus are usually detected in the skin and the eye, although heavily infected individuals may occasionally harbor the organisms in blood or urine. To examine skin for microfilariae, blood-free biopsies are obtained from the interscapular region and gluteal area of Africans and deltoids of Central Americans $(36,44)$. This is done with a scleral punch or sharp razor blade and should be almost painless when done quickly. The specimen is then weighed, placed in a small volume of culture medium (e.g., RPMI 1640) or saline, and allowed to incubate for several hours. Microfilariae that have emerged from the skin are counted by inspection under a dissecting microscope. Provocative tests utilizing DEC to induce itching and erythema (i.e., Mazzotti reaction) should not be done since this may precipitate ocular disease (47). Demonstration of microfilariae in the eye usually requires the aid of a slit lamp. Tilting the patient's head forward for several minutes before examination increases the probability of detecting microfilariae in this location. Direct examination of the eye with an ophthalmoscope may reveal microfilariae in fluffy opacities in the cornea.

\section{Serologic Assays}

The inherent insensitivity of parasitologic methods for diagnosis of infection in persons with no or low intensities of microfilariae in blood or subcutaneous tissue has prompted the development of serologic assays. As is the case with other infectious diseases, the presence of serum antibodies, especially when obtained at one time point only, does not reliably distinguish between past infection and active infection, in which live adult filariae are present. Several investigators have measured circulating antigen levels to detect infection in amicrofilaremic patients and possibly as an indirect index of adult-worm burden $(39,143)$. The Gib 13 and BP-1 monoclonal antibody-based assays were found to detect infection in a portion of amicrofilaremic adults (39, 82). These assays are not specific for lymphatic filariasis, however, as the monoclonal antibodies utilized to trap serum antigen were subsequently determined to be directed against phosphocholine epitopes (72). Phosphocholine is found in several other infectious agents $(50,107)$. Other antigens such as those shared with the dog heartworm Dirofilaria immitis have also been tested in the field (140), but to date none have proven to be both specific and sensitive enough for general use.

The development of circulating antigen assays for onchocerciasis has proven to be even more problematic than for lymphatic filarial infections, because of the relatively high levels of circulating immune complexes which develop in the infection (22). DNA probes which are sensitive and specific for the filarial species of interest have recently been developed and may represent a diagnostic approach superior to antibody- or antigen-based methods $(37,86,106,122-124)$.

\section{CHEMOTHERAPY OF HUMAN FILARIASIS}

DEC has been the standard chemotherapy for all forms of human filariasis. Recent studies with the macrocyclic lactone ivermectin, an agent widely used in veterinary medicine, indicate that this drug is significantly safer and at least as effective as DEC in the treatment of onchocerciasis. Ivermectin may also have some advantages over DEC in the chemotherapy of lymphatic filariasis. It should be noted in discussions of currently available agents active against these two major classes of filariae that they are unlikely to have a beneficial effect in individuals with severe eye disease or long-standing lymphatic obstruction.

\section{Lymphatic Filariasis}

DEC acts primarily as a microfilaricidal drug $(80,99)$. Its mechanism of action remains ill defined, although multiple studies suggest that host immune reactivity to microfilariae is modified after administration of the drug and may be required for its antiparasite activity $(80,113)$. Adult worms of $W$. bancrofti are most likely unaffected by conventional doses of DEC. B. malayi adult parasites appear to become necrotic after administration of the drug to humans (80).

A variety of dosage regimens have been used. A cumulative dose of $72 \mathrm{mg} / \mathrm{kg}$ of body weight given over a 2- to 3 -week period is successful in reducing the intensity of microfilaremia by $>90 \%$ for a period of 6 to 12 months (116, 117). Practical problems with administration of DEC in this manner to large populations in tropical areas of the world has led to testing several alternative schedules, including a medicated salt form and lower doses as prophylaxis $(4,67$, $96,116)$. Long-term weekly administration to a total dosage that may kill adult worms (e.g., $144 \mathrm{mg} / \mathrm{kg}$ ) has also been proposed (99). These regimens require further testing in the field.

Toxicity from DEC is of two general types. Direct toxicity is dose related, manifested as nausea and vomiting, and related to central nervous system effects of DEC $(116,117)$. Toxicity occurs in uninfected as well as infected individuals and can be avoided by giving the drug in smaller, divided, daily doses. The other major form of toxicity occurs in infected persons only and appears to be secondary to death of microfilariae. The symptoms include fever, nausea and vomiting, headache, prostration, and, in the most severely affected individuals, asthmatic attacks. These may appear within 1 to 2 days of initiating therapy and occur concomitantly with an acute drop in microfilaremia $(12,13)$. Their severity is minimized by initiating therapy with approximately one-quarter of the calculated dose and gradually reaching full doses after 3 to 4 days.

Direct comparisons of the efficacy of ivermectin and DEC in the treatment of lymphatic filariasis have not yet been performed in large numbers of individuals in various endemic areas. However, preliminary data reported from India and the South Pacific suggest that ivermectin has microfilaricidal activity equivalent to DEC and fewer side effects and that it is easier to administer (single oral dose) (24).

\section{Onchocerciasis}

DEC was used for many years to treat $O$. volvulus infection and had well-known side effects, including pruritus, lymphadenitis, fever, and, more seriously, hypotension, keratitis, and optic neuritis $(44,80)$. Since the pathologic response in onchocerciasis is related primarily to host reactions to microfilariae and since complications of DEC therapy include acute visual impairment (48), there has been an urgent need to identify effective and safe microfilaricidal drugs for this infection. Initial trials with ivermectin without comparison to other drugs (3) have been followed by direct comparisons of ivermectin to standard therapy with DEC (48). These studies have clearly established the superiority of ivermectin over DEC in terms of safety, patient tolerance, 
and short-term microfilaricidal activity. Doses of 100 to 200 $\mu \mathrm{g} / \mathrm{kg}$ of body weight given once by the oral route reduces the intensity of microfilaridermia by $>90 \% 1$ to 6 months after administration. Optimal doses and frequency of administration to prevent development of ocular or skin disease manifestations remain to be established.

\section{Loaiasis}

DEC is currently the primary drug used to treat $L$. loa infection. It appears to not only eliminate microfilariae but also kill adult worms. The drug is given at a dose of 8 to 10 $\mathrm{mg} / \mathrm{kg}$ of body weight per day for 14 to 21 days. Repeated courses of DEC may be required in some individuals. It is important to note that in heavily infected persons microfilariae may migrate to the central nervous system during DEC therapy and cause meningoencephalitis and coma. These persons should be treated initially with lower doses of DEC (e.g., $1 \mathrm{mg} / \mathrm{kg}$ for 3 to 5 days) in combination with corticosteroids (96).

\section{FUTURE DIRECTIONS}

Major advances in our understanding of several aspects of filariases will ultimately lead to improved means of controlling these helminthic infections. First, with respect to epidemiology, efforts should be continued to develop specific and sensitive assays of parasite antigen that reflect adult worm load. Knowledge of this parasitologic index will permit accurate longitudinal assessment of the impact of vector eradication, chemotherapy, and vaccine programs. Emphasis should also be placed on the development of chemotherapy that kills adult worms of $O$. volvulus, $W$. bancrofti and $B$. malayi. More detailed understanding of the biochemical pathways unique to this parasite stage and not present in the mammalian host may provide a fruitful approach for the design of drugs. Finally, an understanding of the immunopathologic and protective role of $\mathrm{B}$ - and T-cell responses to specific parasite antigens will ultimately underlie the development of a vaccine to eradicate or control the infection in endemic areas. Based on studies of other helminthic infections, emphasis should be placed on defining epitopes that elicit T-cell helper or inducer responses and IgE antibodies.

\section{LITERATURE CITED}

1. Anderson, J., H. Fuglsang, and P. J. S. Hamilton. 1974. Studies on onchocerciasis in the United Cameroon Republic. I. Comparison of populations with and without Onchocerca volvulus. Trans. R. Soc. Trop. Med. Hyg. 68:190-208.

2. Arasu, P., M. Philipp, and F. Perler. 1987. Brugia malayi. Recombinant antigens expressed by genomic DNA clones. Exp. Parasitol. 64:281-291.

3. Aziz, M. A., S. Diallo, I. M. Diop, M. Lariviere, and M. Porta. 1982. Efficacy and tolerance of ivermectin in human onchocerciasis. Lancet ii:171-273.

4. Bryan, J. N., and B. A. Southgate. 1976. Some observations on filariasis in Western Somoa after mass administration of diethylcarbamazine. Trans. R. Soc. Trop. Med. Hyg. 70:3948.

5. Buck, A. A., R. I. Anderson, and K. Kawata. 1969. Onchocerciasis: some new epidemiologic and clinical findings. Am. J. Trop. Med. Hyg. 18:217-230.

6. Burren, C. H. 1972. The behavior of Brugia malayi microfilariae in experimentally infected domestic cats. Ann. Trop. Med. Parasitol. 66:235-242.

7. Caballero, C. E., and A. Barrera. 1958. Estudios helmintologicos de la region oncocercosa de Mexico y de la Republica de
Guatemala. Nematoda 11a Parte. Filarioidea V. Halazgo de un nodulae oncocercosa en un mono arana. Ateles geoffroyi vellerosus Gray, del Estado de Chiapas. Rev. Latinoam. Microbiol. 1:79-94.

8. Cameron, T. W. M. 1928. On a species of Onchocerca from an ox in West Africa. J. Helminthol. 6:161-164.

9. Canlas, M., A. Wadee, L. Lamontagne, and W. F. Piessens. 1984. A monoclonal antibody to surface antigens on microfilariae of Brugia malayi reduces microfilaremia in infected jirds. Am. J. Trop. Med. Hyg. 33:420-624.

10. Canlas, M. M., and W. F. Piessens. 1985. Stage-specific and common antigens of Brugia malayi identified with monoclonal antibodies. J. Immunol. 132:3138-3144.

11. Chea, S. N., and R. E. Howells. 1979. The uptake in vitro of dyes, monosaccharides, and amino acids by the filarial worm Brugia pahangi. Parasitology 78:343-354.

12. Ciferri, F. E., and J. F. Kessel. 1967. Relation of age, sex, and microfilaria density to treatment of sub-periodic filariasis with diethylcarbamazine. Am. J. Trop. Med. Hyg. 16:321-328.

13. Coggeshall, L. T. 1946. Filariasis in the serviceman. Retrospect and prospect. J. Am. Med. Assoc. 131:8-12.

14. Comley, J. C. W., and J. J. Jaffe. 1983. Retinol and filarial glycoprotein synthesis. Trans. R. Soc. Trop. Med. Hyg. 77: 136.

15. Connor, D. H. 1978. Current concepts in parasitology. Onchocerciasis. N. Engl. J. Med. 298:379-381.

16. Connor, D. H., G. H. George, and D. W. Gibson. 1985. Pathologic changes of human onchocerciasis: implications for future research. Rev. Infect. Dis. 7:809-819.

17. Court, J. P., R. C. Murgatroyd, D. Livingstone, and E. Rahr. 1988. Physiochemical characteristics of non-electrolytes and their uptake by Brugia pahangi and Dipetalonema viteae. Mol. Biochem. Parasitol. 27:101-108.

18. Dalmat, H. T. 1958. The black-flies (Diptera, Simuliidae) of Guatemala, their role as vectors of onchocerciasis. Smithsonian Misc. Collect. 125:425.

19. DeLeon, R. J., and B. O. L. Duke. 1966. Experimental studies on the transmission of Guatemalan and West African strains of Onchocerca volvulus by Simulium ochraceum, $S$. metallicum and S. callidum. Trans. R. Soc. Med. Hyg. 60:735-752.

20. Denham, D. A., and P. B. McGreevy. 1977. Brugian filariasis. Adv. Parasitol. 17:243-308.

21. Dennis, D. T., F. Partono, Purnomo, S. Atmosoedjono, and J. S. Saroso. 1976. Timor filariasis: epidemiologic and clinical features in a defined community. Am. J. Trop. Med. Hyg. 25: 797-802.

22. Des Moutis, I., A. Ouassi, J. M. Grzych, L. Yarzabal, A. Haque, and A. Capron. 1985. Onchocerca volvulus: detection of circulating antigen by monoclonal antibodies in human onchocerciasis. Rev. Infect. Dis. 7:831-836.

23. Desowitz, R. S., and J. C. Hitchcock. 1974. Hyperendemic bancroftian filariasis in the Kingdom of Tonga: the application of the membrane-filter technique to an age-stratified blood survey. Am. J. Trop. Med. Hyg. 23:877-879.

24. Diallo, S., M. A. Aziz, O. Ndir, S. Badiane, I.B. Bah, and O. Gaye. 1987. Dose-ranging study of ivermectin in treatment of filariasis due to Wuchereria bancrofti. Lancet i: 1030 .

25. Disney, R. H. L., and P. F. L. Borcham. 1969. Blood gorged resting blackflies in Cameroon and evidence of zoophily in Simulium damnosum. Trans. R. Soc. Trop. Med. Hyg. 63:286288.

26. Dondero, T. J., N. C. Bhattachorya, and H. R. Black. 1976. Clinical manifestations of bancroftian filariasis in a suburb of Calcutta, India. Am. J. Trop. Med. Hyg. 25:64-73.

27. Dondero, T. J., Jr., S. Sivanandam, and C. C. Lee. 1971. Diurnally subperiodic microfilarial pattern in Brugia malayi in West Malaysia. Trans. R. Soc. Trop. Med. Hyg. 65:691-693.

28. Duke, B. O. L. 1960. Studies on the biting habits of Chrysops. VII. The biting cycles of nulliparous and parous $C$. silace $a$ and C. dimidiata (bombe form). Ann. Trop. Med. Parasitol. 54: 147-155.

29. Duke, B. O. L. 1962. Experimental transmission of Onchocerca volvulus to chimpanzees. Trans. R. Soc. Trop. Med. 
Hyg. 56:271-280.

30. Duke, B. O. L. 1967. Onchocerca Simulium complexes. IV. Transmission of a variant of a forest strain of Onchocerca volvulus. Ann. Trop. Med. Parasitol. 61:200-208.

31. Duke, B. O. L. 1968. Studies on factors influencing transmission of onchocerciasis. IV. The biting cycles, infective biting density, and transmission potential for forest Simulium damnosum. Ann. Trop. Med. Parasitol. 62:95-106.

32. Duke, B. O. L. 1970. Onchocerca-Simulium complexes. VI. Experimental studies on the transmission of Venezuelan and West African strains of Onchocerca volvulus by Simulium metallicum and $S$. exiguum in Venezuela. Ann. Trop. Med. Parasitol. 64:421-431.

33. Duke, B. O. L., and W. N. Beelsey. 1958. The vertical distribution of Simulium damnosum bites on the human body. Ann. Trop. Med. Parasitol. 52:274-281.

34. Duke, B. O. L., D. J. Lewis, and J. P. Moore. 1966. Onchocerca-Simulium complexes. 1. Transmission of forest and Sudansavanna strains of Onchocerca volvulus from Cameroon by $S$. damnosum of various West African bioclimatic zones. Ann. Trop. Med. Parasitol. 60:318-335.

35. Duke, B. O. L., J. P. Moore, and R. J. DeLeon. 1967. Onchocerca-Simulium complexes. V. The intake and subsequent fate of microfilariae of a Guatemalan strain of Onchocerca volvulus in forest and Sudan-savanna forms of the West African Simulium damnosum. Ann. Trop. Med. Parasitol. 61: 332-337.

36. Duke, B. O. L., P. D. Scheffel, J. Guyon, and J. P. Moore. 1967. The concentration of Onchocerca volvulus microfilariae in skin snips taken over twenty-four hours. Ann. Trop. Med. Parasitol. 61:216-219.

37. Erttmann, K. D., T. R. Unnasch, B. M. Greene, E. J. Albiez, J. Boateng, A. M. Denke, J. J. Ferraroni, M. Karam, H. SchulzKey, and P. N. Williams. 1987. A DNA sequence specific for forest form Onchocerca volvulus. Nature (London) 327:415417.

38. Fain, A. 1978. Les problemes actuals de la loase. Bull. W.H.O. 56:155-167.

39. Forsyth, K. P., R. Spark, J. Kazura, G. Brown, P. Peters, P. Heywood, S. Dissanayake, and G. F. Mitchell. 1985. A monoclonal antibody-based immunoradiometric assay for detection of circulating antigen in bancroftian filarasis. J. Immunol. 134: 1172-1179.

40. Franke, E. D., and P. O. Weinstein. 1984. In vitro cultivation of Dipetalonema viteae third-stage larvae: evaluation of culture media, serum and other supplements. J. Parasitol. 70:618-628.

41. Gallin, M., K. Edmonds, J. J. Ellner, K. D. Erttmann, A. T. White, H. S. Newland, H. R. Taylor, and B. M. Greene. 1988. Cell-mediated immune responses in human infection with Onchocerca volvulus. J. Immunol. 140:1999-2007.

42. Garm, R. 1983. Studies of the transmission of Onchocerca volvulus by species of the Simulium damnosum complex occurring in Liberia. Z. Angew. Zool. 70:101-117.

43. Gibson, D. W., and D. H. Connor. 1978. Onchocercal lymphadenitis: clinicopathologic study of 34 patients. Trans. R. Soc. Trop. Med. Hyg. 72:137-154.

44. Greene, B. M. 1984. Onchocerciasis, p. 413-422. In K. S. Warren and A. A. F. Mahmoud (ed.), Tropical and geographical medicine. McGraw-Hill Book Co., New York.

45. Greene, B. M., M. M. Fanning, and J. J. Ellner. 1983. Non-specific suppression of antigen-induced lymphocyte blastogenesis in Onchocerca volvulus infection in man. Clin. Exp. Immunol. 52:259-265.

46. Greene, B. M., A. A. Gbakima, E. J. Albiez, and H. R. Taylor. 1985. Humoral and cellular immune responses to Onchocerca volvulus infection in humans. Rev. Infect. Dis. 7:787-798.

47. Greene, B. M., H. R. Taylor, E. J. Brown, R. L. Humphrey, and T. J. Lawley. 1983. Ocular and systemic complications of diethylcarbamazine therapy for onchocerciasis: association with circulating immune complexes. J. Infect. Dis. 147:890897.

48. Greene, B. M., H. B. Taylor, E. W. Cupp, R. P. Murphy, A. T. White, M. A. Aziz, H. Schultz-Key, S. A. D'Anna, H. S.
Newland, L. P. Goldschmidt, C. Auer, A. P. Hanson, S. V. Freeman, E. W. Reber, and P. N. Williams. 1985. Comparison of ivermectin and diethylcarbamazine in the treatment of onchocerciasis. N. Engl. J. Med. 313:133-138.

49. Grove, D. I., F. Valeza, and B. D. Cabrera. 1978. Bancroftian filariasis in a Philippine village: clinical, parasitological, immunological and social aspects. Bull. W.H.O. 56:975-984.

50. Gualzate, M., N. Weiss, and C. H. Heusser. 1986. Dipetalonema viteae: phosphorylcholine and non-phosphorylcholine antigenic determinants in infective larvae and adult worms. Exp. Parasitol. 61:95-99.

51. Guptavanij, P., and C. Harinasuta. 1971. A note on sheathed and unsheathed appearance of periodic and subperiodic Brugia malayi in southern Thailand. Southeast Asian J. Trop. Med. Public Health 2:94-95.

52. Guptavanij, P., C. Harinasuta, S. Suchavi, and S. Vutikes. 1971. Studies on subperiodic Brugia malayi in Southern Thailand. Southeast Asian J. Trop. Med. Public Health 2:44-50.

53. Hawking, F. 1967. The 24-hour periodicity of microfilariae: biological mechanisms responsible for its production and control. Proc. R. Soc. London Ser. B 169:56-76.

54. Hawking, F. 1973. The distribution of human filariasis throughout the world. II. Asia. W.H.O. publication WHO/FIL/73.114. World Health Organization, Geneva.

55. Hawking, F., and K. Gammage. 1968. The periodic migration of microfilariae of Brugia malayi and its response to various stimuli. Am. J. Trop. Med. Hyg. 17:724-729.

56. Hawking, F., S. Pattaayak, and H. L. Sharma. 1966. The periodicity of microfilariae. 1 . The effect of body temperature and other stimuli upon the cycles of Wuchereria bancrofti, Brugia malayi, B. ceylonensis and Dirofilaria repens. Trans. $\mathbf{R}$. Soc. Trop. Med. Hyg. 60:497-513.

57. Hayashi, Y., K. Noda, A. Shirasaka, S. Nogami, and M. Nakamura. 1984. Vaccination of BALB/c mice against Brugia malayi and Brugia pahangi with larvae attenuated by gamma irradiation. Jpn. J. Exp. Med. 52:177-189.

58. Hussain, R., M. Grugl, and E. A. Ottesen. 1987. IgG antibody subclasses in human filariasis: differential subclass recognition of parasite antigens correlates with different clinical manifestations of infection. J. Immunol. 139:2794-2798.

59. Hussain, R., and E. A. Ottesen. 1985. IgE responses in human filariasis. III. Specificites of IgE and IgG antibodies compared by immunoblot analysis. J. Immunol. 135:1415-1421.

60. Hussain, R., and E. A. Ottesen. 1986. IgE responses in human filariasis. IV. Parallel antigen recognition by IgE and IgG4 subclass antibodies. J. Immunol. 136:1859-1866.

61. Jaffe, J. J., and L. R. Chrin. 1981. Involvement of tetrahydrofolate cofactors in de novo purine ribonucleotide synthesis by adult Brugia pahangi and Dirofilaria immitis. Mol. Biochem. Parasitol. 2:259-270.

62. Jeffers, G. W., T. R. Klei, and F. M. Enright. 1984. Activation of jird (Meriones unguiculatus) macrophages by the filarial parasite Brugia pahangi. Infect. Immun. 43:43-48.

63. Kazura, J. W., H. Cicirello, and K. P. Forsyth. 1986. Differential recognition of a protective filarial antigen by antibodies from humans with bancroftian filariasis. J. Clin. Invest. 77: 1985-1992.

64. Kazura, J. W., H. Cicirello, and J. W. McCall. 1986. Induction of protection against Brugia malayi infection in jirds by microfilarial antigens. J. Immunol. 136:1422-1426.

65. Kazura, J. W., and R. S. Davis. 1982. Soluble Brugia malayi microfilarial antigens protect mice against challenge by an antibody-dependent mechanism. J. Immunol. 128:1792-1796.

66. Kazura, J. W., R. Spark, K. Forsyth, G. Brown, P. Heywood, P. Peters, and M. Alpers. 1984. Parasitologic and clinical features of bancroftian filariasis in a community in East Sepik Province, Papua New Guinea. Am. J. Trop. Med. Hyg. 33: 1119-1123.

67. Kimura, E., L. Penaia, and G. F. S. Spears. 1985. The efficacy of annual single-dose treatment with diethylcarbamazine citrate against diurnally subperiodic bancrofitan filariasis in $\mathrm{Sa}$ moa. Bull. W.H.O. 63:1097-1106.

68. Lagraulet, J., A. G. M. Monjusiau, and N. Dessolle. 1966. 
Action du Mel W. sur les nodules et sur la postioite des biopsies dans l'onchocercose (resultats observes 22 mois apres une injection unique de $7 \mathrm{mg}$. 5 par kilogramme de poids). Bull. Soc. Pathol. Exot. 59:986-990.

69. Laing, A. B. G., J. E. B. Edeson, and R. H. Wharton. 1961. Studies on filariasis in Malaya: further experiments on the transmission of Brugia malayi and Wuchereria bancrofti. Ann. Trop. Med. Parasitol. 55:86-92.

70. Lal, R. B., T. J. Lynch, and T. B. Nutman. 1987. Brugia malayi antigens associated with lymphocyte activation in filariasis. $\mathbf{J}$. Immunol. 139:1652-1657.

71. Lal, R. B., and E. A. Ottesen. 1988. Characterization of stage-specific antigens of infective larvae of the filarial parasite Brugia malayi. J. Immunol. 140:2032-2038.

72. Lal, R. B., R. S. Paranjape, D. E. Briles, T. B. Nutman, and E. A. Ottesen. 1987. Circulating parasite antigen(s) in lymphatic filariasis: use of monoclonal antibodies to phosphocholine for immunodiagnosis. J. Immunol. 138:3454-3458.

73. Leeuwin, R. S. 1962. Microfilaremia in Surinamese living in Amsterdam. Trop. Geogr. Med. 14:355-360.

74. Lewis, D. J. 1968. Reviews of some recent research on Onchocerca vectors. Trans. R. Soc. Trop. Med. Hyg. 62:19-21.

75. Lewis, D. J., R. H. L. Disney, and R. W. Crosskey. 1969. A new phoretic species of Simulium from West Cameroon, with taxónomic notes on allied forms. Bull. Entomol. Res. 59:229 239.

76. Lewis, D. J., and P. W. Hanney. 1965. On the Simulium neavei complex (Diptera: Simuliiudae). Proc. R. Entomol. Soc. London Ser. B 34:12-16.

77. Longworth, D. L., D. C. King, and P. F. Weller. 1987. Rapid uptake and esterification of arachidonic acid and other fatty acids by microfilariae of Brugia malayi. Mol. Biochem. Parasitol. 23:275-284.

78. Longworth, D. L., R. A. Monaham-Earley, A. M. Dvorak, and P. F. Weller. 1988. Brugia malayi: arachidonic acid uptake into lipid bodies of adult parasites. Exp. Parasitol. 65:251-257.

79. Lucius, R., D. W. Buttner, C. Kirsten, and H. J. Diesfield. 1986. A study on antigen recognition by onchocerciasis patients with different clinical forms of disease. Parasitology 92:569-580.

80. MacKenzie, C. D. 1985 . Diethylcarbamazine: a review of its action in onchocerciasis, lymphatic filariasis and inflammation. Trop. Dis. Bull. 82:R1-R36.

81. MacKenzie, C. D., J. F. Williams, B. M. Sisley, M. M. Steward, and J. O'Day. 1985. Variations in host responses and the pathogenesis of human onchocerciasis. Rev. Infect. Dis. 7: 802-808.

82. Maizels, R. M., D. A. Denham, and I. Sutanto. 1985. Secreted and circulating antigens of the filarial parasite Brugia pahangi: analysis of in vitro released components and detection of parasite products in vivo. Mol. Biochem. Parasitol. 17:277288.

83. Mattingly, P. E. 1969. The biology of mosquito-borne disease. George Allen and Unwin Ltd., London.

84. Mattingly, P. E. 1973. Culicidae, p. 37-108. In K. G. E. Smith (ed.), Insects and other arthropods of medical importance. British Museum, London.

85. McGreevy, P. B., S. Ratiwayanto, S. Tuti, M. M. McGreevy, and D. T. Dennis. 1980. Brugia malayi: relationship between anti-sheath antibodies and amicrofilaremia in natives living in an endemic area of South Kalimantan, Borneo. Am. J. Trop. Med. Hyg. 29:553-562.

86. McReynolds, L. A., S. M. DeSumone, and S. A. Williams. 1986. Cloning and comparison of a repeated DNA sequence from the human filarial parasite Brugia malayi and the animal parasite Brugia pahangi. Proc. Natl. Acad. Sci. USA 83:797-801.

87. Mendis, A. H. W., and S. Townson. 1985. Evidence for the occurrence of respiratory electron transport in adult Brugia pahangi and Dipetalonema viteae. Mol. Biochem. Parasitol. 14:337-356.

88. Nelson, G. S. 1970. Onchocerciasis. Adv. Parasitol. 8:173-224.

89. Ngu, J. L. 1978. Immunological studies on onchocerciasis. Acta Trop. 35:269-279.

90. Nilsen, T. W., P. A. Maroney, R. G. Goodwin, K. G. Perrine,
A. J. Denker, J. Nanduri, and J. W. Kazura. 1988. Cloning and characterization of a potentially protective antigen in lymphatic filariasis. Proc. Natl. Acad. Sci. USA 85:3606-3607.

91. Nutman, T. B., V. Kumaraswami, L. Pao, P. R. Narayanan, and E. A. Ottesen. 1986. Analysis of in vitro B cell immune responsiveness in human lymphatic filariasis. J. Immunol. 138: 3954-3959.

92. Nutman, T. B., K. D. Miller, M. Mulligan, and E. A. Ottesen. 1986. Loa loa infection in temporary residents of endemic regions: recognition of a hyperresponsive syndrome with characteristic clinical manifestations. J. Infect. Dis. 154:10-18.

93. Nutman, T. B., E. A. Ottesen, A. S. Fauci, and D. J. Volkman. 1984. Parasite antigen-specific human T cell lines and clones. J. Clin. Invest. 73:1754-1762.

94. Nutman, T. B., W. Reese, R. W. Poindexter, and E. A. Ottesen. 1988. Immunologic correlates of the hyperresponsive syndrome in loaisis. J. Infect. Dis. 157:544-550.

95. Oothuman, P., D. A. Denham, P. B. McGreevy, G. S. Nelson, and R. Rogers. 1979. Successful vaccination of cats against Brugia pahangi with larvae attenuated by irradiation with 10 Krad cobalt 60. Parasite Immunol. 1:209-215.

96. Ottesen, E. A. 1984. Filariases and tropical eosinophilia, p. 390-412. In K. S. Warren and A. A. F. Mahmoud (ed.), Tropical and geographical medicine. McGraw-Hill Book Co., New York.

97. Ottesen, E. A. 1984. Immunologic aspects of lymphatic filariasis and onchocerciasis. Trans. R. Soc. Trop. Med. Hyg. 78(Suppl.):9-18.

98. Ottesen, E. A. 1984. Immunopathology of lymphatic filariasis in man. Springer Semin. Immunopathol. 2:373-385.

99. Ottesen, E. A. 1985. Efficacy of diethylcarbamazine in eradicating infection with lymphatic-dwelling filariae in humans. Rev. Infect. Dis. 7:341-356.

100. Ottesen, E. A. 1985 . Immediate hypersensitivity responses in the immunopathogenesis of human onchocerciasis. Rev. Infect. Dis. 7:796-801.

101. Ottesen, E. A., F. A. Neva, R. S. Paranjape, S. P. Tripathy, K. V. Thiruvengadam, and M. A. Beaven. 1979. Specific allergic sensitization to filarial antigens in tropical eosinophilia syndrome. Lancet i:1158-1161.

102. Ottesen, E. A., F. Skavaril, S. P. Tripathy, R. W. Poindexter, and R. Hussain. 1985. Prominence of IgG4 in the IgG antibody response to human filariasis. J. Immunol. 134:2707-2711.

103. Ouassi, M. A., J. P. Dessaint, J. Cornette, I. Desmoutis, and A. Capron. 1983. Induction of non-specific human suppressor cells in vitro by defined Onchocerca volvulus antigens. Clin. Exp. Immunol. 53:634-642.

104. Pappas, P. W., and C. P. Read. 1975. Membrane transport in helminth parasites: a review. Exp. Parasitol. 37:469-530.

105. Partono, F., Purnomo, and W. Pribaldi. 1978. Epidemiological and clinical features of Brugia timori in a newly established village, Karakuak, West Flores, Indonesia. Am. J. Trop. Med. Hyg. 27:910-915.

106. Perler, F. B., and M. Karam. 1986. Cloning and characterization of two Onchocerca volvulus repeated DNA sequences. Mol. Biochem. Parasitol. 21:171-178.

107. Perry, P., A. Petit, J. Pulian, and G. Luffau. 1974. Phosphorylcholine bearing components in homogenates of nematodes. Eur. J. Immunol. 4:637-646.

108. Petralanda, I., L. Yarzabal, and W. F. Piessens. 1986. Studies on a filarial antigen with collagenase activity. Mol. Biochem. Parasitol. 19:51-59.

109. Piessens, W. F., P. B. McGreevy, P. W. Piessens, J. McGreevy, I. Koiman, J. S. Saroso, and D. T. Dennis. 1980. Immune responses in human infections with Brugia malayi. Specific cellular unresponsiveness to filarial antigens. J. Clin. Invest. 65:172-179.

110. Piessens, W. F., P. B. McGreevy, S. Ratiwayanto, M. McGreevy, P. W. Piessens, I. Koiman, S. Saroso, Jr., and D. T. Dennis. 1980. Immune responses in human infections with Brugia malayi: correlation of cellular and humoral reactions to microfilarial antigens with clinical status. Am. J. Trop. Med. Hyg. 31:953-957. 
111. Piessens, W. F., and F. Partono. 1980. Host-vector-parasite relationships in human filariasis. Semin. Infect. Dis. 3:131-152.

112. Piessens, W. F., F. Partono, S. L. Hofiman, S. Ratiwayanto, P. W. Piessens, J. R. Palmieri, I. Koiman, D. T. Dennis, and W. P. Carney. 1982. Antigen-specific suppressor T lymphocytes in human lymphatic filariasis. N. Engl. J. Med. 307:144 148.

113. Piessens, W. F., S. Ratiwayanto, P. W. Piessens, S. Tuti, P. B. McGreevy, F. Darwis, J. R. Palmieri, I. Koiman, and D. T. Dennis. 1981. Effect of treatment with diethylcarbamazine on immune responses to filarial antigens in patients infected with Brugia malayi. Acta Trop. 38:227-234.

114. Powell, J. W., J. N. Stables, and R. A. Walt. 1986. An investigation of the glucose metabolism of Brugia pahangi and Dipetalonema viteae by nuclear magnetic resonance spectroscopy. Mol. Biochem. Parasitol. 18:171-182.

115. Raghavan, N. G. S. 1969. A review of epidemiology of filariasis in India. J. Commun. Dis. 1:153-194.

116. Sasa, M. 1976. Human filariasis-a global survey of epidemiology and control. University Park Press, Baltimore.

117. Sasa, M., T. Oshima, K. Sato, G. Mitsui, F. Sugata, S. Nishi, H. Yamanoto, I. Tada, and E. Motoi. 1963. Studies on epidemiology and control of filariasis: observations on the carriers of Wuchereria bancrofti in the Armami Islands with special reference to the effects and side reactions of diethylcarbamazine. Jpn. J. Exp. Med. 33:213-243.

118. Schrater, A. F., A. Spielman, and W. F. Piessens. 1983. Predisposition to Brugia malayi microfilaremia in progeny of infected gerbils. Am. J. Trop. Med. Hyg. 32:1306-1308.

119. Scientific Working Group. 1976. Epidemiology of onchocerciasis. W.H.O. Tech. Rep. Ser. 597:1-94.

120. Scientific Working Group. 1981. The immunology of filariasis. Bull W.H.O. 59:1-8.

121. Selkirk, M. E., D. A. Denham, F. Partono, I. Sutanto, and R. M. Maizels. 1986. Molecular characterization of antigens of lymphatic filarial parasites. Parasitology 93:515-524.

122. Shah, J. S., M. Karam, W. F. Piessens, and D. F. Wirth. 1987 Characterization of an Onchocerca-specific DNA clone from Onchocerca volvulus. Am. J. Trop. Med. Hyg. 37:376-384.

123. Shah, J. S., L. Lamontagne, T. R. Unnasch, D. F. Wirth, and W. F. Piessens. 1986. Characterization of a ribosomal DNA clone of B. malayi. Mol. Biochem. Parasitol. 19:67-75.

124. Sim, B. K. L., J. W. Mak, W. H. Cheong, I. Sutanto, L. Kurniawan, H. A. Marwoto, E. Franke, J. R. Campbell, and D. F. Wirth. 1986. Identification of Brugia malayi in vectors with a species-specific DNA probe. Am. J. Trop. Med. Hyg. 35:559-564.

125. Southgate, B. A. 1979. Bancroftian filariasis in Egypt. Trop. Dis. Bull. 76:1045-1068.

126. Steward, J. W., B. Sisley, C. D. MacKenzie, and H. El Sheikh. 1982. Circulating antigen-antibody complexes in onchocerciasis. Clin. Exp. Immunol. 48:17-24.

127. Stone, A., K. L. Knight, and H. Starcke. 1959. A synoptic catalogue of the mosquitoes of the world. Entomological Society of America, Washington, D.C.

128. Strong, R. P. 1937. Onchocerciasis in Central America and Africa. Trans. R. Soc. Trop. Med. Hyg. 30:487-506.

129. Taylor, A. E., and D. A. Denham. 1986. Immunology and diagnosis of filariasis. Trop. Dis. Bull. 83:R1-R20.

130. Turner, L. H., and J. F. B. Edeson. 1957. Studies on filariasis in Malaya: the periodicity of the microfilariae of Wuchereria malayi. Ann. Trop. Med. Parasitol. 51:271-277.

132. Valeza, F., and D. I. Grove. 1979. Bancroftian filariasis in a Philippine village: entomological findings. Southeast Asian J. Trop. Med. Hyg. 10:51-61.

133. Van den Berghe, L., M. Chardome, and E. Peel. 1964. The filarial parasites of the Eastern Gorilla in the Congo. J. Helminthol. 38:349-368.

134. Vincent, A. L., A. C. Vickery, M. J. Lotz, and U. Desai. 1984. The lymphatic pathology of Brugia pahangi in nude (athymic) and thymic $\mathrm{C} 3 \mathrm{H} / \mathrm{HeN}$ mice. J. Parasitol. 70:48-56.

135. von Brandt, T. 1973. Biochemistry of parasites. Academic Press, Inc., New York.

136. von Lichtenberg, F. 1957. The early phase of endemic bancroftian filariasis in the male-pathologic study. J. Mt. Sinai Hosp. 6:983-1000.

137. von Lichtenberg, F. 1987. Inflammatory responses to filarial connective tissue parasites. Parasitology 94(Suppl.):101-122.

138. Wang, E. J., and H. S. Saz. 1974. Comparative biochemical studies of Litomosoides carinii, Dipetalonema viteae and Brugia pahangi adults. J. Parasitol. 60:316-321.

139. Ward, D. J., T. B. Nutman, G. Zea-Flores, C. Portocarrero, A. Lujan, and E. A. Ottesen. 1988. Onchocerciasis and immunity in humans: enhanced $\mathrm{T}$ cell responsiveness to parasite antigen in putatively immune individuals. J. Infect. Dis. 157:536-543.

140. Weil, G. J., H. Kumar, S. Santhanam, K. V. P. Sethumadhavan, and D. C. Jain. 1986. Detection of circulating parasite antigen in bancroftian filariasis by counterimmunoelectrophoresis. Am. J. Trop. Med. Hyg. 35:565-570.

141. Weil, G. J., K. G. Powers, E. L. Parbuoni, B. R. Line, R. D. Furrow, and E. A. Ottesen. 1982. Dirofilaria immitis. VI. Antimicrofilarial immunity in experimental filariasis. Am. J. Trop. Med. Hyg. 31:477-485.

142. Weinstein, P. P. 1986. Filariasis: problems and challenges. Am. J. Trop. Med. Hyg. 35:221-233.

143. Wenger, J. D., K. P. Forsyth, and J. W. Kazura. 1988 Identification of phosphorylcholine epitope-containing antigens in Brugia malayi and relation of serum epitope levels to infection status of jirds with brugian filariasis. Am. J. Trop. Med. Hyg. 38:133-141.

144. Wharton, R. H. 1962. The biology of Mansonia mosquitoes in relation to the transmission of filariasis in Malaya. Bull. Inst. Med. Res. Fed. Malaya 11:114.

145. Wharton, R. H. 1963. Adaptation of Wuchereria and Brugia to mosquitoes and vertebrate hosts in relation to the distribution of filarial parasites. Zoonoses Res. 2:1-12.

146. Wijers, D. J. B., and H. Kinyanjui. 1977. Bancroftian filariasis in Kenya. II. Clinical and parasitological investigations in Mambrin, a small coastal town and Jaribuni, a rural area more inland (Coastal Province). Ann. Trop. Med. Parasitol. 71:333345.

147. Williams, J. F., M. EI Khalifa, C. D. MacKenzie, and B. Sisley. 1985. Antigens of Onchocerca volvulus. Rev. Infect. Dis. 7: 831-836.

148. Wolfe, M. S., and M. Aslamakham. 1972. Bancroftian filariasis in two villages in Dinajpur, East Pakistan. I. Infections in man. Am. J. Trop. Med. Hyg. 21:22-29. 